\title{
The impact of emotional intelligence on work performance- An empirical investigation
}

\author{
R. Bhuvaneswari ${ }^{1, *}$ Dr. P. Natarajan ${ }^{2}$ \\ ${ }^{1} \mathrm{PhD}$. Student, ${ }^{2}$ Professor, Dept. of Commerce, Pondicherry University, Pondicherry, India \\ *Corresponding Author: \\ Email: rtbhuvaneswari@gmail.com
}

\begin{abstract}
The Emotional Intelligence (EI) is an imperative concept to meet thought of the structure goals via better work performance of the executives working in the organization. In this study was planned to check the character and pattern of an empirical investigation among the performance of work and EI of executives working in the banking sector. Interview schedules consisting of 16 items (EI) and 15 items (work performance) were used. The findings of this study showed that work performance in scheduled commercial bank executives has high degree of correlation with EI.
\end{abstract}

Keywords: Emotional Intelligence, Work performance, Organizational goal, Positive emotion, Interpersonal communication.

\section{Introduction}

Emotional Intelligence (EI), is an essential arena in an organizational psychology and social psychology has been attracted conjointly the attentiveness of structural behaviour, as a result of its crucial role at the workplace (Wong and Law, 2002). EI origins are often making out at the construct of social intelligence, in the first instance reflecting the dexterity of an individual to handle with feelings. EI have expanded this description recommended to different cerebration, surrounding motivation, non-capable inclinations and courtesy, and interpersonal and intrapersonal competencies were functioning (Mayer and Salovey, 2000). Mentioned below, many analytical studies have delivered supporting proof that EI is a crucial predecessor of task allied outcomes like turnover, intention to quit, satisfaction of work, and work performance (WP) (Thamos sy and O'Hara, 2006). Specifically, EI develop ability of approach of the customers, provided that the efficiency of banking sectors scheme depends upon on workers' contentment and their ability to produce better quality of services (Ioan Pastor, 2014). Furthermore, executive's absences are well tried to be connected with contrary events and aspects of banking inefficiency. Hence, this derives of more prominence to explore work performance and its amelioration in the banking sector (Priyam Dhani et al., 2016). High turnover, especially in service sectors, become a global phenomenon (Panagiotis Trivella et al., 2013). Several studies showed that the intention of continuing an employment stems since factors like leadership support, organization commitment, and work fulfillment (Price, L.J., 2001). In addition, several researchers delivered proof of an adverse affinity between EI and work attitude. Such social control problems are approached in numerous studies with the use of process strategies (Chi-Sum Wong, 2002). Although very truths that work performance, emotional debility and personality of executives were investigated thoroughly, there is restricted analysis upon work issues and signficantly work performance of bank executives. The present study aims to investigate the interactions among the work performance (WP) and four dimensions of EI.

\section{Review of literature}

This article validates on EI influence of work performance backbone theories of perceive ability concerning the emotional and social overhead of Goleman models (2000).

\section{Conceptual foundations}

Minarova (2014) deliberates EI to be a crucial vicinity of executive's competency. Its define competency as probity of executive's ability (collected of 3 pillars -smart and application skills, general and technical abilities and self and social maturity), and competencies (duty, responsibility and authority). It's a lot of perceives EI is a bedrock of social maturation by demanding that the highest level competency of executives (balance between its components) can be an important necessity to successful of associate degree organization in gratifying its vision and mission. Mura, (2013) associated degree of leadership subject needs to attain success within the long run; it ought to actively collaborate with its workers, as they are results of the carriers and conjointly the single house holders of their bloke wealth. Boyatzis, R. E (2000) defines EI as a result of the flexibility to manage individual feelings, and regulate emotions, that want to be steered in an extremely acceptable and efficient suggests that therefore on collaborate with totally different memberships of a bunch, in attaining related purposes. Claims that the quality of EI is not determined by biological science, nor it's plagued by babyhood development. The potentials of EI persuade to be emerging inside the long-term, and it ought to be identified that these qualities are usually learned. Martina .M (2015) understands EI as a vicinity of the smart part of knowledge, i.e. the capacity to utilize 
feelings in social circumstances: understanding one's own particular feelings, inspiration, capacity to perform self-assessment and self-control (intrapersonal segments of EI), and at indistinguishable present compassionate and having social abilities-intercede successfully to various individuals' favorable position (relational segments of EI).

\section{Research background \\ EI in banking sector}

The dynamic of EI have been vastly predictable for the circumstance of bank executives employed in banking sectors. Each member of a Bank's employees needs to face, in a day to day activities, with events bound with emotions like financial regulation, sensible environment. Thus, banking executive need to regulate stressful circumstances obligatory by the working location besides on the similar period they stand given grateful perform in the most effective way. Great responsibility upon customers' approach is utmost importance, provided that its absence might affect cost of their life. Additionally, these stressful factors inside banking sectors require impact on executive's work performance and turnover intentions (Thomas Sy., et al 2006). Controversy of EI has been empirically sustained by more than few scientists, specifically in the last decade, there some proof EI plays an enormous character upon the turnover intention that may probably lead to real deserting and therefore, EI ought to be additional surveyed predictor of such behavior (Chiu, C.K. \& Francesco, M.A., 2003). The above mentioned controversy becomes of a better position under the consideration that banking sectors try to give enhanced lead to high quality of services provided to customers (Cooper, R. K., \& Sawaf, A. 1997). Even though there is wide discussion $\&$ ambiguity regarding the meanings of EI, maximum of the researchers are proposing corresponding instead of contrasting conceptions \& 4 different EI aspects has been appeared in this measurement (Ciarrochi, J. V., et al 2000). Building on this area, the four-dimensioned of instrument WLEIS have designed by Wong and Law (2002) as specified below:

1. Self-emotional assessment-SEA (assessment and manifestation of self-emotions): This facet measures the person's ability to express and grasp deep emotions.

2. Others' emotional assessment-OEA (appraisal and identification of others emotion): This dimension replicates the person's skills to understand \& perceive the feelings of them surrounding people.

3. Regulation of emotion-ROE (Self-emotional regulation): Estimates this element person's ability use of emotional identify, facilitating its speedy and positive revitalization next psychologically suffering.

4. Use of emotion-UOE (emotional use of facilitates performance): In this element reverberate the person's ability towards direct \& utilize emotions to productive actions \& peculiar presentation.

\section{EI and work performance}

EI fabricate positive work attitudes and altruistic behaviors (Sy, Thomas 2006). The EI executives were enjoy with tend to expertise a lot of positive moods and emotions and to be a lot of deliver better performance of their working employment, since they have additional dexterous at assessing directing and regulating self-feelings in distinction to those have a lesser overall EI (Wong \& Law, 2002). EI executives ought to be enhanced at recognizing emotions of disappointment and frustration, moreover as their main drivers, and in this way they may control their feelings and enhance systems and tirelessness to manage their negative impacts (Cooper, R. K., and Sawaf, A. (1997). Then again, officials have less EI points are missing behind in having abilities to get a handle on and deal with their feelings after they are taking care of extreme and muddled circumstances, and subsequently they receive lopsided practices escalating negative emotions and lessening their work execution levels (Mafuzah Mohamad, 2016). Besides, officials with high EI could encourage collaboration by abusing their capacity to comprehend, evaluate and oversee feelings of their partners. Amid way of this, they contribute can decidedly to the certainty and resolve of the bunch, upgrading team and separate fulfillment at the working environment for all individuals (Shimazu, A., \& Odahara, T. 2004). Slaski and Cartwright (2002) steered that management performance and EI have considerably positive relationship. Nevertheless, the connection between EI and work performance appeared to be reasonable due to growing tendency of executives accepting under consideration EI candidates during selection and recruitment process conjointly in employee's improvement programs.

\section{Conceptual framework}

In the present adopted the theoretical framework dependent on the literatures reviewed as designated below.

Based on the literature reviews from previous, the succeeding hypothesis was established and examined which confirms the EI positive influence on work performance of executives employed in scheduled commercial banking sectors in Puducherry. Consideration based on this result, the primary hypothesis of the analysis is explained as mention below:

H1: EI stands correlated with work performance positively. 


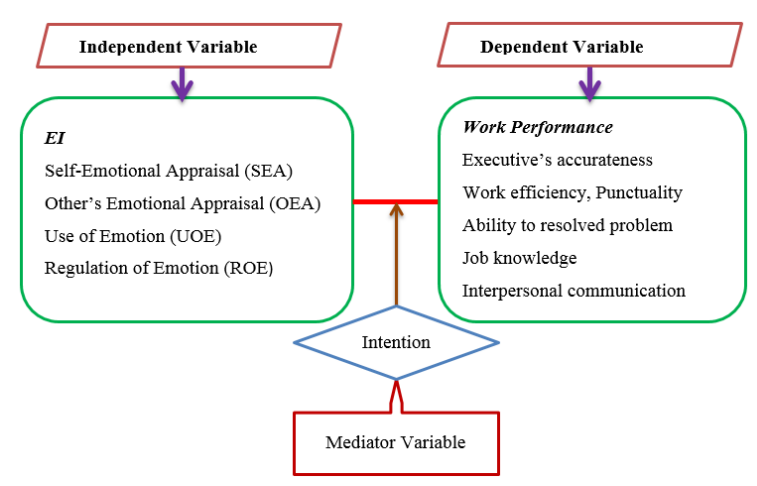

Fig. 1: A theoretical framework affiliation between EI and work performance

\section{Materials and Method}

Current study attempts to investigate the EI influence of work performance. The field research was conducted in all scheduled commercial banks in the area of Puducherry, India. Structured interview schedule were dispersed to 310 executives but 230 valid interview schedules were reimbursed. The convenience sampling technique method was used testing sampling design. The sample sizes were selected from 1700 population using by statistic formula for defining sample size confirm from a given population. Finally sample sizes were decided at 226. The sample size measurement formula mentioned below;

$$
n=\frac{Z^{2} p q}{d^{2}}
$$

$\mathrm{n}$ - Total preferred size of samples

$\mathrm{Z}$ - The normal Standard Deviation regularly fixed at 1.96 (which significant at the 95 percent level of confidence)

$\mathrm{p}$ - The quantity within target of population possesses particular distinctive. If approximation obtainable set at 50 percent (or .5)

$$
\mathrm{q}-1-\mathrm{p}
$$
.05 .

d - Exactly accuracy or precision normally set at

Reply of respondent's degree was $75.3 \%$ maximum executives' age series started 26 - 45 years old $(71.6 \%)$. The majority tenure of experience showed $11-15$ years (50.5\%), and the 60.1 percent of the respondents grasps a graduate from Educational Institutes of Technologies. During the present study, EI were determined with the
WLEIS instrument Wong and Law designed it contains sixteen items grouped in four factors as follows: the first one SEA second is OEA, third one is UOE and the final one is ROE. Its robust coming together with prior EI determines like the EO-i and the Trait Meta-Mood and is analytically confirmed. Moreover, Wang and Law EIS can predictability extraneous variables wise life gratification and WP. Besides, many Doctoral scholars have validated and utilized this construct. Work performance is measured using six dimension of self-assessment interview schedule. It measures various aspects of performance, like executive's accurateness, Work efficiency, Punctuality, Ability to resolved problem, Job knowledge and Interpersonal communication. This scale supply elevated validity, more internal reliability and familiarizes adequately to different structure contexts. Purpose to deviate were considered by using these items of interview schedule of Wong and Law et al., (2002) which is similarly measured to deliver high validity. Responses were assessed five point likert scales. The higher values don't invariably mirror excellent performance, which is some greater value of represents give poorer presentation that's known as negative emotions. The subsequent calculation stands consumed to measurement our EI index used mentioned below formula.

$$
\text { EI Index }=\frac{\sum \text { SEIV }_{\mathrm{i}}}{\sum \mathrm{MSEIV}_{\mathrm{i}}} \times 100
$$

Whereas: SEIV - Score on EI Variables MSEIV - Maximum Score on EI Variables $\mathrm{i}=1 \ldots \mathrm{n}-$ Number of EI Variables.

\section{Results and Discussion}

Analyzed the data using the partial least squares (PLS) through path modeling approach the Smart-PLS software 3.0 (Dekoulou, P \& Trivellas P, 2014). The variance-centered PLS technique could be latent variable forming method that integrates numerous dependent constructs and it is measured to be helpful in investigation descriptive and prognostic relationships significantly with samples of 226 respondents. A powerful improvement PLS method of associated covariance-based SEM ability to face with conditions wherever information regarding.

Table 1: Analyze the convergent, discriminant validity and reliability of all variables

\begin{tabular}{|l|l|l|l|l|l|l|l|l|l|l|l|l|l|l|}
\hline & Ave & CR & $\begin{array}{c}\alpha \\
\text { Alpha }\end{array}$ & SEA & OEA & ROE & UOE & WE & PTY & PD & OB & JK & IC & WP \\
\hline SEA & .826 & .818 & .860 & $\mathbf{. 9 0 9}$ & & & & & & & & & & \\
\hline OEA & .737 & .805 & .863 & .329 & $\mathbf{. 8 5 8}$ & & & & & & & & & \\
\hline ROE & .813 & .839 & .851 & .470 & .696 & $\mathbf{. 9 0 5}$ & & & & & & & & \\
\hline UOE & .769 & .830 & .855 & .412 & .689 & .706 & $\mathbf{. 8 7 7}$ & & & & & & & \\
\hline WE & .837 & .863 & .879 & .392 & .827 & .744 & .694 & $\mathbf{. 9 1 5}$ & & & & & & \\
\hline PTY & .824 & .803 & .868 & .233 & .291 & .351 & .349 & .278 & $\mathbf{. 9 0 8}$ & & & & & \\
\hline PD & .869 & .843 & .873 & .308 & .242 & .407 & .319 & .445 & .211 & $\mathbf{. 9 3 2}$ & & & & \\
\hline OB & .857 & .834 & .870 & .228 & .267 & .262 & .204 & .238 & .293 & .397 & $\mathbf{. 9 2 6}$ & & & \\
\hline
\end{tabular}




\begin{tabular}{|l|l|l|l|l|l|l|l|l|l|l|l|l|l|l|}
\hline JK & .797 & .850 & .868 & .367 & .260 & .354 & .319 & .315 & .275 & .438 & .392 & $\mathbf{. 8 9 3}$ & & \\
\hline IC & .868 & .890 & .874 & .294 & .191 & .374 & .297 & .357 & .330 & .401 & .409 & .445 &. $\mathbf{9 3 1}$ & \\
\hline WP & .895 & .898 & .878 & .437 & .290 & .400 & .310 & .241 & .221 & .401 & .311 & .238 & .293 & $\mathbf{. 9 4 6}$ \\
\hline
\end{tabular}

The average square root of value showed in the bold color, off-sloping fundamentals are coefficients of correlation among the variables dispersion latent variable is limited, necessities regarding the intimacy between assessments and also information ought to be met and the small sample size (Fornell, C, 1994). Also, a minimum size of sample that's 10 times biggest the variety of operational ways directed at a selected construct within the internal path model is suggested by Barclay, D. Thompson, R. \& Higgins, C (2009). The dependent variable with the biggest variety of predictor variables is personal development this variety is 6 . Thus, the sample size ought to be a minimum of sixty. Supported this recommendation meets the size of sample necessities of PLS. PLS preceding, the Bartlett sphericity analysis on the degree of relationship between the variables $(\mathrm{p}<0.001)$ and also appropriateness of the sample in keeping with KaiserMeyer-Olkin (KMO over .70) verified the appropriateness of the sample. Henseler et al., (2009) said PLS model instructed ought to be developed in 2 stages: the measuring model and also the structural model. The measuring model examines the relations between MV (manifest variables) and LV (latent variables). The structural model is concentrated on the analysis of the validity and dependableness of the concepts within the model. Composite reliability (CR) and Cronbach's alpha $(\alpha)$ were measured to assess the reliability of scales. All constructs revealed CR and $\alpha$ higher than the least acceptable level of .7 (Nunnally, J.C et al.,) as mentioned in the table one. The 4 dimensional LV of EI still because the unidimensionality confirmed were strength of emotional constructs. On the opposite hand, examining the work performance scale six major mechanisms reflective performance with work efficiency (WE), puntuality (PTY), public dealing (PD), obedience (OB), job knowledge (JK) and interpersonal communication (IC) were derived.

Fornell and Lacker's (1994) AVE (average variance extracted) principle is established for the assessment of scales' convergent validity (CV). Average level of LV ought to be more than .5, so as to elucidate quite half the variance of its indicators on the average (Dekoulou,P., et al and Henseler, J., et al., 2009). As revealed in table one, all variables met this criterion. Additionally, $\mathrm{CV}$ of a variable is also evaluated by exploratory the factor loadings of the things on the model's constructs. High items' loadings on their rudimentary construct and lower loadings on unrelated constructs designate CV. Barclay et al., projected those items' loadings of .7 or higher offer proof for CV. In this study, factor loadings of all items on their individual associated constructs are unit higher than $.8(\mathrm{p}<0.01)$, whereas their loadings on dissimilar constructs are lower than .4. Discriminant validity of the measuring model was scrutinized through Fornell and Larcker's (1994) AVE tests a look at and correlations criterion. This test a look at describes that square root of the relevant AVE every construct ought to be surpass the relationships amongst the aspects creating every paralelism.

This event, every component portions a lot of difference with its peculiar chunk of pointers than with another component representing a distinct block of indicators. As revealed in table one, all constructs in this analysis model established adequate discriminant validity, since the diagonal parts that are unit the sq. roots of the class Aves, are unit higher than the offdiagonal parts (correlations) within the corresponding columns and rows.

Table 2: Analysis of all variables convergent and discriminant validity results

\begin{tabular}{|c|c|c|c|c|c|c|}
\hline & Items & Communality & Redundancy & $\mathbf{R}^{\mathbf{2}}$ & CV- Communality & CV-Redundancy \\
\hline SEA & 4 & .766 & & & .736 & .710 \\
\hline OEA & 4 & .851 & & & .818 & \\
\hline ROE & 4 & .788 & & & .777 & \\
\hline UOE & 4 & .868 & & & .505 & .438 \\
\hline WE & 3 & .825 & .046 & .683 & .707 & \\
\hline PTY & 2 & .694 & & & .656 & \\
\hline PD & 3 & .728 & & & .672 & .389 \\
\hline OB & 2 & .635 & & & .653 & \\
\hline JK & 3 & .659 & .043 & .569 & & \\
\hline IC & 2 & .828 & & & & \\
\hline
\end{tabular}

The improvising technique consuming 226 samples were conducted to compute the structural model and predominantly, the applied math significance of all parameter estimates. The PLS SEM model is especially evaluated by $R^{2}$ of endogenous $L V$, result size $\left(\mathrm{f}^{2}\right)$,
Goodness of fit (GoF), and by consuming the StoneGeiser Q2 test a look at for prognostic connection. Chin characterized $\mathrm{R}^{2}$ values of .61, .32, and .19 for endogenous LV as substantial, moderate and weak severally. Results confirmed nearly substantial $\mathrm{R}^{2}$ 
values in this study, as shown in table two. The GoF index was utilized to judge the match of the model, and for our model it's .746, which means that the model is ready to require into consideration $74.6 \%$ of the doable match. The Q2 statistics value the prognostic connection of the model, whereas a score beyond zero means the model has prognostic connection. In this study, two types of Q2 statistics unit are calculate, those are: (a) cross-validated communality $(\mathrm{H} 2 \mathrm{j})$ and (b) cross-validated redundancy ( $\mathrm{F} 2 \mathrm{j})$. In accordance to result size (f2), the q2 values of $0.06,0.15$, and 0.35 signify tiny, medium, and huge prognostic connection of certain latent variable. As shown in table number two, all values indicate robust prognostic connection of the relevant latent variable.

Table 3: Correlation between EI and work performance

\begin{tabular}{|c|c|c|c|c|c|c|c|c|c|c|c|}
\hline & WP & SEA & OEA & ROE & UOE & OB & WE & PTY & PD & JK & IC \\
\hline WP & 1 & & & & & & & & & & \\
\hline SEA & $.425^{* *}$ & 1 & & & & & & & & & \\
\hline OEA & $.346^{* *}$ & $.697^{* *}$ & 1 & & & & & & & & \\
\hline ROE & $.535^{* *}$ & $.714^{* *}$ & $.710^{* *}$ & 1 & & & & & & & \\
\hline UOE & $.440^{* *}$ & $.709^{* *}$ & $.843^{* *}$ & $.751^{* *}$ & 1 & & & & & & \\
\hline WE & $.810^{* *}$ & $.278^{* *}$ & $.219^{* *}$ & $.278^{* *}$ & $.187^{* *}$ & 1 & & & & & \\
\hline PTY & $.726^{* *}$ & $.445^{* *}$ & $.211^{* *}$ & $.463^{* *}$ & $.301^{* *}$ & $.509^{* *}$ & 1 & & & & \\
\hline PD & $.779^{* *}$ & $.238^{* *}$ & $.293^{* *}$ & $.397^{* *}$ & $.345^{* *}$ & $.296^{* *}$ & $.554^{* *}$ & 1 & & & \\
\hline OB & $.621^{* *}$ & $.315^{* *}$ & $.275^{* *}$ & $.438^{* *}$ & $.392^{* *}$ & $.488^{* *}$ & $.533^{* *}$ & $.302^{* *}$ & 1 & & \\
\hline JK & $.793^{* *}$ & $.357^{* *}$ & $.330^{* *}$ & $.401^{* *}$ & $.409^{* *}$ & $.346^{* *}$ & $.487^{* *}$ & $.563^{* *}$ & $.545^{* *}$ & 1 & 1 \\
\hline IC & $.746^{* *}$ & $.241^{* *}$ & $.221^{* *}$ & $.401^{* *}$ & $.311^{* *}$ & $.159^{*}$ & $.516^{* *}$ & $.658^{* *}$ & $.486^{* *}$ & $.609^{* *}$ & 1 \\
\hline$* *$ Significantly correlate at the $<.01$ level (2-tailed). \\
\hline *. Significantly correlate at the $<.05$ level (2-tailed). \\
\hline
\end{tabular}

There was a powerful Correlation revealed table three demonstrating that executives EI is positively correlated with the WP offer this primary support for hypothesis one. The sturdiest linear association was found to exist between regulation of emotions and WP that $\mathrm{r}=.535, \mathrm{n}=226, \mathrm{p}<0.01$. The positively correlate coefficient indicated great level of use of EI is related to great level of WP. The next highest value was found be existent between use of EI and WP wherever $\mathrm{r}=.440$, $\mathrm{n}=226, \quad \mathrm{p}<0.01$ and therefore the co-efficient of correlation indicated quite robust relationship between regulation appraisal EI and WP. Third, SEA and WP had quite robust relationship wherever $r=.425, \mathrm{n}=226$, $\mathrm{p}<0.01$ indicated great level of SEA related to high level of WP. Lastly, OEA and WP additionally had quite robust relationship wherever $\mathrm{r}=.346, \mathrm{n}=226$, $\mathrm{p}<0.01$ indicated great level correlation. EI ought to be concerning affectional work outcomes. The ability to use antecedent and response targeted regulation of emotions ought to be alter executives to possess higher affections with colleagues.

\section{PLS analysis}

In way of path connections (standardizedregression-coefficients) model were measurable acting Smart-PLS. The methodology of bootstrap was wont to secure $t$-statistics in order to judge the significance of the parameters. The aftereffects of the parameter estimation are displayed in Fig. 2. No major issues of numerous relationships exist between the independent variables (IV) as Variance Inflation Factors (VIF) is much underneath the three focuses confine taught in Social Sciences analyses.

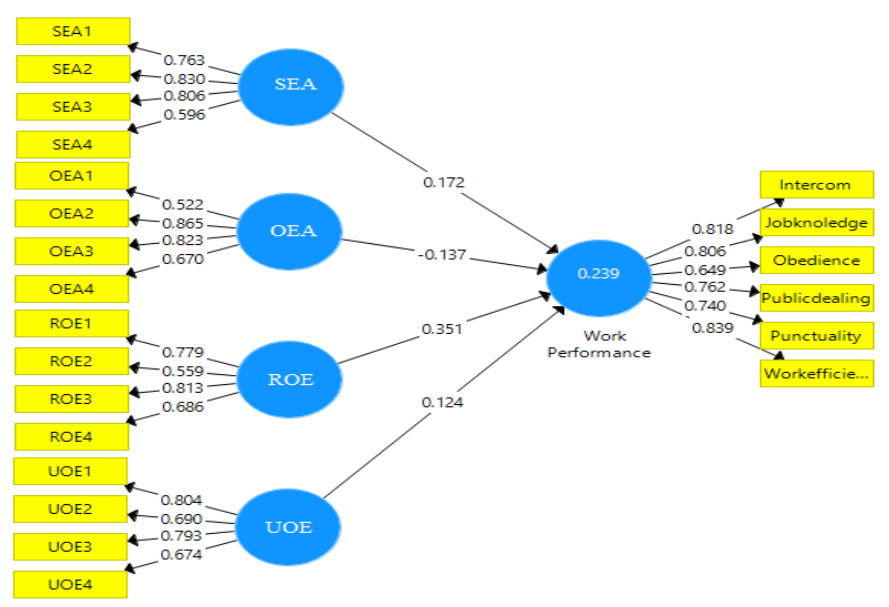

Fig. 2: EI and work performance structural equation model 
This results offer analytical provision for the assumptions that EI exerts a significantly impact on WP. Among the six elements of WP, solely work efficiency (WE) emerged because the most vital dimension extremely related to EI, whereas interpersonal communication (IC) with the working atmosphere $(\mathrm{b}=.818, \mathrm{p}<0.01)$ and quality of $\mathrm{JK}(\mathrm{b}=.806$, $\mathrm{p}<0.01)$ contribute to a considerable proportion of the variance within the WP. Among the four elements of EI, solely SEA, ROE, OEA and UOE confirmed direct associations with WP. Of course, SEA, ROE and UOE exert important positive impact on WP $(b=.172, p<0.01$, $\mathrm{b}=.351, \mathrm{p}<0.01, \mathrm{~b}=.124, \mathrm{p}<0.01$, respectively), whereas they influence negatively others emotional appraisal $(b=-0.137, p<0.01$, respectively). Thus, the result were part supported. Similarly, executives' WP relating to personal development is powerfully and positively concerning others emotional development.

\section{Discussion}

This study investigates the four dimensions of EI and WP. The earlier literature has affirmed vital connections amongst EI and WP to quit. In particular, however numerous researchers have trained a capable connection between EI measurements and occupation fulfillment, findings of this study reveal that especially Use of emotion (UOE), regulation of emotions (ROE) and self-emotional Appraisal (SEA) among this four EI elements square measured with regards to the hypothesized association. These outcomes partly diverge from Shamsuddin N., et al., (2014) discoveries that exclusively ROE is powerfully correlate with WP (both elements of employed environment in internal and external) followed by UOE aspect. Executives are accomplishment with express and appraise their emotions, square measure in an exceptionally position to be higher acknowledged and comprehended by their associates, and therefore, they have the adaptability to create themselves, deal with their vocation way and lead individuals. Moreover, those will expend their feelings to supply numerous \& versatile for their future plans, to boost deciding, to encourage ability and to boost persistence against difficult tasks square measure a lot of informative and operative in handling each positive (happiness) and negative emotions (quitting). Thus, managerial members with high EI (SEA, ROE and UOE) expertise nearly uninterrupted positive attitudes, causation great levels of gratification compared to those that take into account such emotions as distress and disappointment, default to expertise the next level of contentment. In a very similar vein, showing EI executive's square measure doubtless a lot of talented to acknowledge, manage and wieldy their emotions to beat obstacles, improve their ability and dignity and eventually, advance their horizon higher than alternative people. They'll additionally management stress caused by extremely complicated and difficult work environments preventing their negative influences on their professional way. Present study provides supporting proof in concert EI elements (OEA) were unfavorably concerning WP. To determine, analysis not merely established the relations between EI and WP, however additionally hut come across the distinct dimensions of EI, these are SEA, UOE and ROE that articulate these relations, provided that helpful suggestions for administration implications.

\section{Conclusion}

In view of the discussion of this investigation, EI had the association towards WP. Nonetheless, particularly 3 from 4 components of WLEIS had totally impacts toward WP. This is often as a result of the new dimension of WLEIS that resulted from the smartPLS analysis that the self-emotional appraisal (SEA) really was the mixture from the 2 dimensions of WLEIS that the ROE and OEA. This is often as a result of individuals with the flexibility in critical others' feeling and regulate own feeling, had high level of religion and spirit that influence them to form realistic action and result in great performances (Naseer, 2011). EI skill most important for the bank executives as a result of their intention to quit were great compared to alternative industries because of the work stress, occupational environments and alternative connected factors. It's hoped that in this study will offer come to life decision to the organization to pay a lot of attention in the direction of the well-being of their executives by focusing a lot of on psychological and physiological matters. In assumption, there are few commendations that may take into thought for improvement within the future analysis. First, reveal in this study want to be distributed all the sort of schedule commercial banks in order that it may be generalizable to spot the operating atmosphere. Secondly, additional investigation wants to be prepared relating to the measure scale that WLEIS so as to work out the foremost applicable things for every dimension will offer higher leads to the long run. Third one, the banking sector will adapt WLEIS or alternative EI measure scale as tool to judge potential candidates' status throughout the choice and achievement method. This is often vital in guaranteeing the suitableness of the candidates with the work duties. Finally, the bank executives will conduct coaching in personal development in order that their staff will have a far better understanding in characteristic, understanding and managing their self-emotions then particularly emotions of their coworkers and therefore the valuable clients.

\section{References}

1. Barclay, D., Higgins, C., \& Thompson, R. (1995). The Partial Least Squares (pls) Approach to Casual Modeling: Personal Computer Adoption Ans Use as an Illustration.

2. Bourne, M., Pavlov, A., et al. 2013. Generating organizational performance: The contributing effects of performance measurement and human resource management practices. International Journal of 
Operations \& Production Management, 33(11/12), 15991622.

3. Boyatzis, R. E., Goleman, D., \& Rhee, K. 2000.

Clustering competence in EI: Insights from the Emotional Competence Inventory (ECI). Handbook of EI, 99(6), 343-362.

4. Carmeli, A. 2003. The relationship between EI and work attitudes, behavior and outcomes: An examination among senior managers. Journal of managerial Psychology, 18(8), 788-813.

5. Chiu, C. K., Chien, S.C., Lin, P.C. \& Hsiao, Y.C., 2005. Understanding hospital employee job stress and turnover intentions in a practical setting: The moderating role of locus of control. Journal of Management Development, 24, 837-855.

6. Ciarrochi, J. V., Chan, A. Y., \& Caputi, P. 2000. A critical evaluation of the EI construct. Personality and Individual differences, 28(3), 539-561.

7. Cooper, R. K., \& Sawaf, A. 1997. EI in business. Orion.

8. Dekoulou, P., \& Trivellas, P. (2014). Learning Organization in Greek Advertising and Media Industry: A way to face crisis and gain sustainable competitive advantage. Procedia-Social and Behavioral Sciences, 148, 338-347.

9. Fornell, C., \& Cha, J. (1994). Partial least squares. In Bagozzi, R.P. (Ed.), advanced methods of marketing research, Cambridge: Basil Blackwell. (pp. 52-78).

10. Henseler, J., Ringle, C. M., \& Sinkovics, R. R. (2009). The use of partial least squares path modeling in international marketing. In New challenges to international marketing (pp. 277-319). Emerald Group Publishing Limited.

11. Khokhar, C P. 2009. "EI and WP among Executives." Europe's Journal of Psychology, 1-11.

12. Law, K.S., Wong, C.S. \& Song, L.J. 2004. The construct and criterion validity of EI and its potential utility for management studies, Journal of Applied Psychology, 89, 3, 483-496.

13. Martina, M., Denisa, M., \& Mariana, S. 2015. EI of Managers. Procedia Economics and Finance, 26, 11191123.

14. Mayer, J. D., Caruso, D. R., \& Salovey, P. 2000. EI meets traditional standards for intelligence. Intelligence, 27, 4, 267-298.

15. Minarova, M., 2014. "EI as part of the manager's competence Banska Bystrica" Publisher of Matej Bel University - Belianum.

16. Mohamad, Mafuzah, and Juraifa Jais. 2016. "EI and Job Performance : A Study among Malaysian Teachers." Procedia Economics and Finance 35(October 2015): 67482. http://dx.doi.org/10.1016/S2212-5671 (16)00083-6.

17. Naseer, Z., Chishti, S. U. H., Rahman, F.,. 2011. Impact of EI on Team Performance in Higher Education Institutes. International Online Journal of Educational Sciences, 3(1).

18. Nunnally, J.C., \& Bernstein, I.H. 1994. Psychometric Theory, 3rd edition. New York: McGraw -Hill.

19. Pastor, Ioan. 2014. "Leadership and EI : The Effect on Performance and Attitude." Procedia Economics and Finance 15(14): 985-92.

20. Price, L.J., 2001. Reflections on the determinants of voluntary turnover. International Journal of Manpower, 22, 600-624.

21. Priyam Dhani, Anil Sehrawat, and Tani Sharma, 2016. "Relationship between EI and Job Performance: A Study in Indian Context." Indian Journal of Science and Technology, Vol 9(47), DOI: 10.17485/ijst/2016/v9i47/103064.
22. Ringle, C. M., Wende, S., \& Will, A. 2005. SmartPLS 2.0 (M3) beta. Hamberg, Germany: University of Hamberg, Retrieved 11th June, 2012, from http://www.smartpls.de.

23. Shamsuddin, Noorazzila, and Abdul Rahman. 2014. "The Relationship between EI and Job Performance of Call Centre Agents." Procedia - Social and Behavioral Sciences 129: 75-81.

24. Shimazu, A., Shimazu, M., \& Odahara, T. 2004. Job control and social support as coping resources in job satisfaction. Psychological Reports, 94(2), 449-456.

25. Slaski, M., \& Cartwright, S. 2002. Health, performance and EI: An exploratory study of retail managers. Stress and health, 18(2), 63-68.

26. Sy, Thomas, Susanna Tram, and Linda A O Hara. 2006. "Relation of Employee and Manager EI to Job Satisfaction and Performance.” Journal of Vocational Behavior, 68: 461-73.

27. Trivellas, Panagiotis, Vassilis Gerogiannis, and Sofia Svarna. 2013. "Exploring Workplace Implications of EI (WLEIS) in Hospitals : Job Satisfaction and Turnover Intentions." Procedia-Social and Behavioral Sciences 73: 701-9.

28. Wong, Chi-sum, and Kenneth S Law. 2002. "The Effects of Leader and Follower EI on Performance and Attitude : An Exploratory Study." The Leadership Quarterly 13: 243-274. 